\title{
Befriending led to a higher frequency of overall remission in women with chronic depression
}

\author{
Harris T, Brown $G W$, Robinson R. Befriending as an intervention for chronic depression among women in an inner city. \\ I: randomised controlled trial. Br J Psychiatry 1999 Mar;174:219-24.
}

\section{Question}

In women with chronic depression, does volunteer befriending improve symptoms and increase recovery?

\section{Design}

Randomised, unblinded, controlled trial with follow up to 1 year.

\section{Setting}

Inner city London, UK.

\section{Patients}

86 patients (age concentration $25-40$ y) recruited through a postal screening of all women registered with certain general practices in Islington. The clinical interview to determine whether chronic depression was at a caseness level used an abbreviated form of the shortened Present State Examination (PSE-10, 4 out of 10 core symptoms had to be present along with depressed mood). Exclusion criteria were severe comorbid conditions of substance misuse or eating disorders, or lack of interest in the provisional offer of befriending.

\section{Intervention}

43 patients were assigned to befriending and 43 to a wait list control group. Volunteers to befriend were recruited through advertisement, were interviewed and trained by social workers, and were matched to the 43 patients in the befriending group. Befriending was defined as meeting and talking with the woman who was depressed for a minimum of 1 hour each week and acting as a "friend" to her, listening, and "being there" for her.

\section{Main outcome measure}

Overall remission (minimum 2 mo and included partial remission) based on the PSE-10.

\section{Main results}

Analysis was by intention to treat. Overall remission occurred more frequently in women in the befriending group than in the control group $\{\mathrm{p}=0.02\} *$ (table). 18 of 43 women $(42 \%)$ allocated to the befriending group met with their volunteer only once or not at all. 10 of these 18 women remitted. Although remission tended to be higher among those receiving the full 12 months of befriending compared with those receiving 2-6 months ( $76 \%$ [ 13 of 17 patients] $v 63 \%$ [5 out of 8 patients]) this difference did not reach statistical significance.

\section{Conclusion}

Befriending led to a higher frequency of overall remission in women with chronic depression.

*p value calculated from data in article.

Befriending $v$ wait list control in women with chronic depressiont

\begin{tabular}{lllll}
\hline Outcome at 1 year & Befriending & $\begin{array}{l}\text { Wait list } \\
\text { control }\end{array}$ & RBI(95\% CI) & NNT (CI) \\
\hline Overall remission & $65 \%$ & $40 \%$ & $65 \%(9$ to 158$)$ & 4 (3 to 23)
\end{tabular}

†Abbreviations defined in glossary; RBI, NNT, and CI calculated from data in article.

Sources of funding: Medical Research Council and the Befriending service funded by contributions from the Joseph Rowntree Foundation; the King's Fund; the Mental Health Foundation; North Thames Regional Health Authority; the Baring Foundation.

For correspondence: Dr Tirril Harris, Socio-Medical Research Centre, Academic Department of Psychiatry, Guy's, King's and St Thomas's Schools of Medicine, St Thomas's Campus, Lambeth Palace Road, London SE1 7EH, UK. Fax +44 (0)1719283951.

\section{Commentary}

Building on their work on the protective role of social support in the onset and course of depressive disorder in women, Harris et al have evaluated a social intervention-befriending-in a randomised trial, and have found it to be effective. There is a considerable choice of treatment modalities of proven efficacy for treating depression, including cognitive therapy, interpersonal psychotherapy, and drug treatments. We have also witnessed an explosion of counselling, an intervention with a much more slender evidence base. Is befriending as effective as other proven treatments?

The size of the benefit for treated women who agreed to enter the trial suggests that it is of the same order of magnitude as for other proven treatments, with a number needed to treat of about 4 . In a companion paper, ${ }^{1}$ the possible mechanisms of action of the intervention are explored. The conclusion of this investigation is that attachment style, positive and negative life events during the year of study, and especially "fresh start" events seem to be important predictors of remission.

Psychosocial treatments are vulnerable to accusations of high cost. In this case, however, treatment was provided by volunteers so the only direct healthcare costs were those of training. The availability of the treatment will be limited to those areas in which suitable volunteers, training, and supervision can be provided.

Although based on a community sample, patients in the present study resemble a secondary care rather than a primary care population because they have been extensively filtered to select only those women whose depressive disorder has been present for at least 1 year. Of most concern in interpreting the findings is the fact that only about 1 in 3 of the suitable patients agreed to be allocated to the befriending treatment. Commentators often remark on the low patient acceptability of drug treatments, but a refusal rate of almost two thirds severely limits the generalisability of the findings, especially in an unblinded trial.

Finally, it is important to remember that this intervention was tested in a centre with expertise and enthusiasm for the intervention. Before the results influence the practice of mental healthcare teams therefore, replication in another centre is desirable.

Robert Peveler, MA, DPhil, BM University of Southampton Southampton, UK

\footnotetext{
1 Harris T, Brown GW, Robinson R. Br J Psychia-
} try 1999;174:225-32. 